\title{
Tribolium beetles as a model system in evolution and ecology
}

\author{
Michael D. Pointer $\mathbb{D}^{1} \cdot$ Matthew J. G. Gage ${ }^{1} \cdot$ Lewis G. Spurgin $\mathbb{D}^{1}$
}

Received: 19 October 2020 / Revised: 19 February 2021 / Accepted: 19 February 2021 / Published online: 25 March 2021

(c) The Author(s) 2021. This article is published with open access

\begin{abstract}
Flour beetles of the genus Tribolium have been utilised as informative study systems for over a century and contributed to major advances across many fields. This review serves to highlight the significant historical contribution that Tribolium study systems have made to the fields of ecology and evolution, and to promote their use as contemporary research models. We review the broad range of studies employing Tribolium to make significant advances in ecology and evolution. We show that research using Tribolium beetles has contributed a substantial amount to evolutionary and ecological understanding, especially in the fields of population dynamics, reproduction and sexual selection, population and quantitative genetics, and behaviour, physiology and life history. We propose a number of future research opportunities using Tribolium, with particular focus on how their amenability to forward and reverse genetic manipulation may provide a valuable complement to other insect models.
\end{abstract}

\section{Introduction}

Research models are fundamental to scientific investigation, providing simplified systems to test and explain components within more complex ideas and hypotheses (Hartmann and Frigg 2005). Model systems can be viewed along a continuum, where simplicity is traded against complex reality, with purely theoretical models at one end, and field-based systems at the other (Winther et al. 2015). Laboratory organisms occupy an intermediate position on this continuum, offering informative opportunities to directly test ecological or evolutionary theory in complex living systems, while retaining high levels of experimental control and allowing for experimental replication. As a result, laboratory models are an essential and widely used tool in biodiversity research, and here we discuss the many applications and strengths that Tribolium beetles possess for research in ecology and evolution.

Associate editor: Frank Hailer

Michael D. Pointer

mdpointer@gmail.com

$\bowtie$ Lewis G. Spurgin

1.spurgin@uea.ac.uk

1 School of Biological Sciences, University of East Anglia, Norwich, UK
In choosing experimental systems, scientists face a choice between focusing effort on one of rather few 'true' model organisms (Sommer 2009), versus adding diversity to the research base, expanding the useful extrapolations that can be made (Bolker 2012). Important distinctions exist between what some consider 'true' model organisms, compared to those used more broadly in experimental studies to which the term is often more loosely applied (Ankeny and Leonelli 2011). Under the more stringent 'animal model' view, the list of model organisms is traditionally limited to very few, including Zea mays (maize), Arabidopsis thaliana (thale cress), the bacterium Escherischa coli, Saccharomyces cerevisiae (yeast), the roundworm Caenorhabditis elegans, the fruitfly Drosophila melanogaster, Xenopus laevis (African clawed frog), Mus musculus (house mouse) and Danio rerio (Zebrafish) (Müller and Grossniklaus 2010). Attributes that distinguish these true model organisms include established research infrastructure, high experimental tractability and the ability to represent broad ranges of both taxa and questions under study (representational scope and representational target respectively, Ankeny and Leonelli 2011). Despite these nine classic models having such attributes, it is clear that we need to consider a wider range of models for progressing research, especially where we aim to tackle questions concerning the evolutionary ecology of biodiversity in the natural environment (Fig. 1).

Tribolium is a genus of small tenebrionid beetles, two of which, $T$. castaneum and $T$. confusum, are significant global 


\section{Tribolium research themes}

Topics in blue boxes form basis of the current review

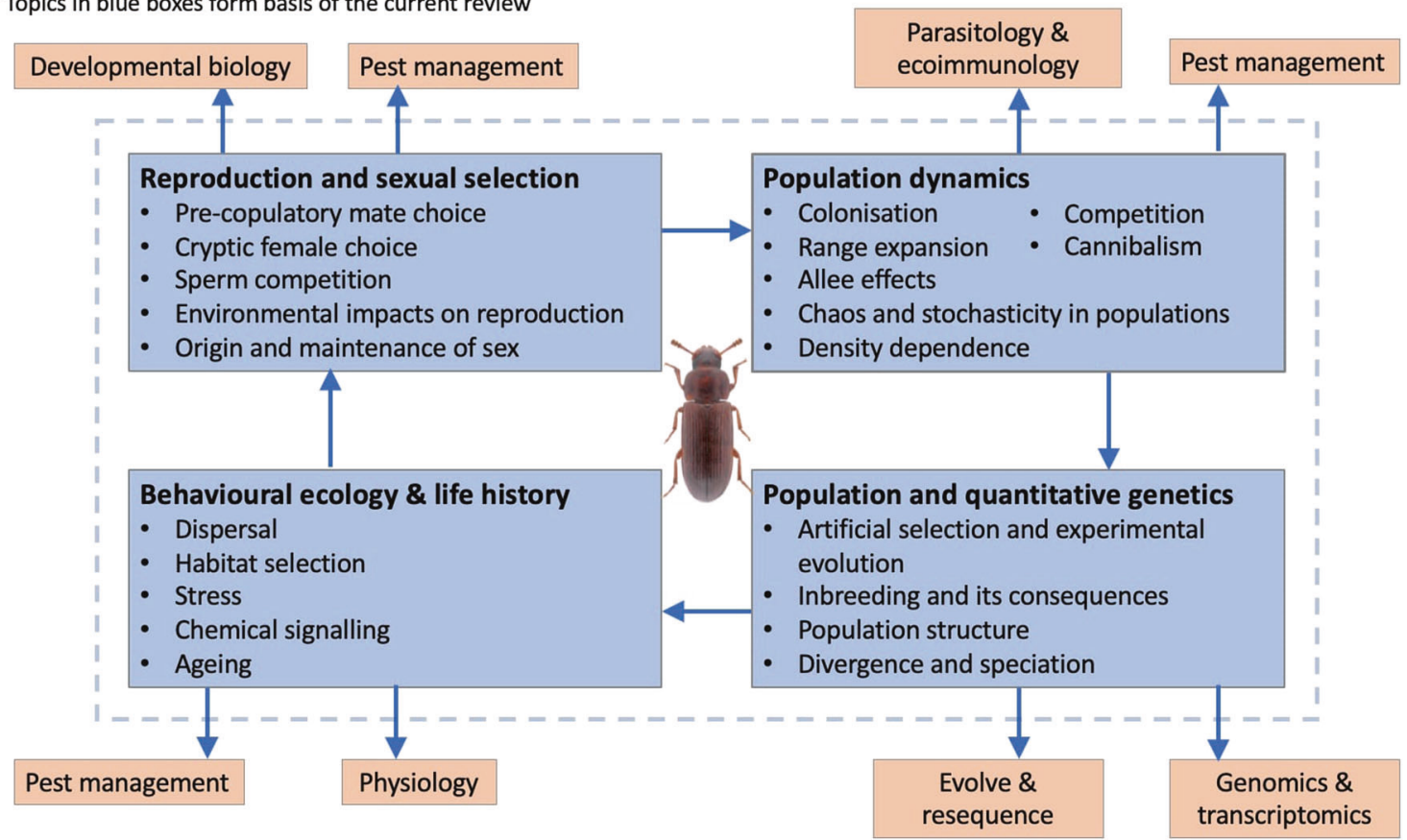

Fig. 1 Tribolium research themes. Panels show interrelationships between research fields within evolution and ecology that have utilised Tribolium beetles as a research model. Those on blue backgrounds form the basis of this review (colour figure online).

pests of stored food products (El-Aziz 2011), and widely used as experimental models (Box 1; Fig. 2). Historically, Tribolium were free-living but are now mainly found infesting stored food products such as flour (Dawson 1977). The original habitat of Tribolium was likely beneath the bark of trees or in rotting wood, where they were secondary colonisers, characterised by rapid population growth and ready dispersal (Dawson 1977). It is not known when these pest species made the switch to a commensal lifestyle with humans, but there is evidence of $T$. confusum from Ancient Egyptian flour urns dating back $\sim 5000$ years, or $\sim 70,000$ beetle generations of selection (Andres 1931).

The purpose of this review is to highlight both the significant historical contribution from Tribolium flour beetles to ecological and evolutionary research, and elaborate their prominence as a contemporary study organism. Tribolium beetles have aided evolutionary ecology research for over a century (Chapman 1918), notably in population biology and interspecific competition (Park 1962), but also across a range of ecological and genetic disciplines. As members of the most species-rich order (Stork et al. 2015), occupying a relatively basal position among the Holometabola (metamorphosing insects), and being less highly derived than Drosophila (the foremost insect model), Tribolium beetles have broad representational scope (Brown et al. 2003). In addition, Tribolium is highly amenable to both forward and reverse genetic manipulation (Brown et al. 2009), a key attribute of any modern model organism (Barr 2003). T. castaneum was the first Coleopteran, and first agricultural pest, to have its genome sequenced (Tribolium Genome Sequencing Consortium et al. 2008), and annotations continue to be updated (Herndon et al. 2020). With the increasing availability of genomic data, biology is likely to become more comparative across models (Hedges 2002). Tribolium occupies a unique position to act as a mediary in the identification of insect orthologs of human genes, breaking a previous reliance on candidate genes from Drosophila and expanding the scope of insect genetics beyond highly conserved regions (Brown et al. 2003). While the Tribolium research infrastructure is certainly less well established than those of Drosophila and C. elegans, it is considerable and growing, with stock centres providing wild-type and many mutant strains to researchers (Brown et al. 2009), and increased availability of genomic and reverse genetic resources (Kim et al. 2010; Dönitz et al. 2015). Finally, this model is also a pest that significantly impacts global food supplies, and understanding gained in the laboratory can be applied to increase global food security (El-Aziz 2011).

Reviews of the Tribolium system exist, but most cover fields such as biomedicine, physiology and particularly developmental biology, where Tribolium is an important model due to its more representative mode of short germ band development than alternative insect models 


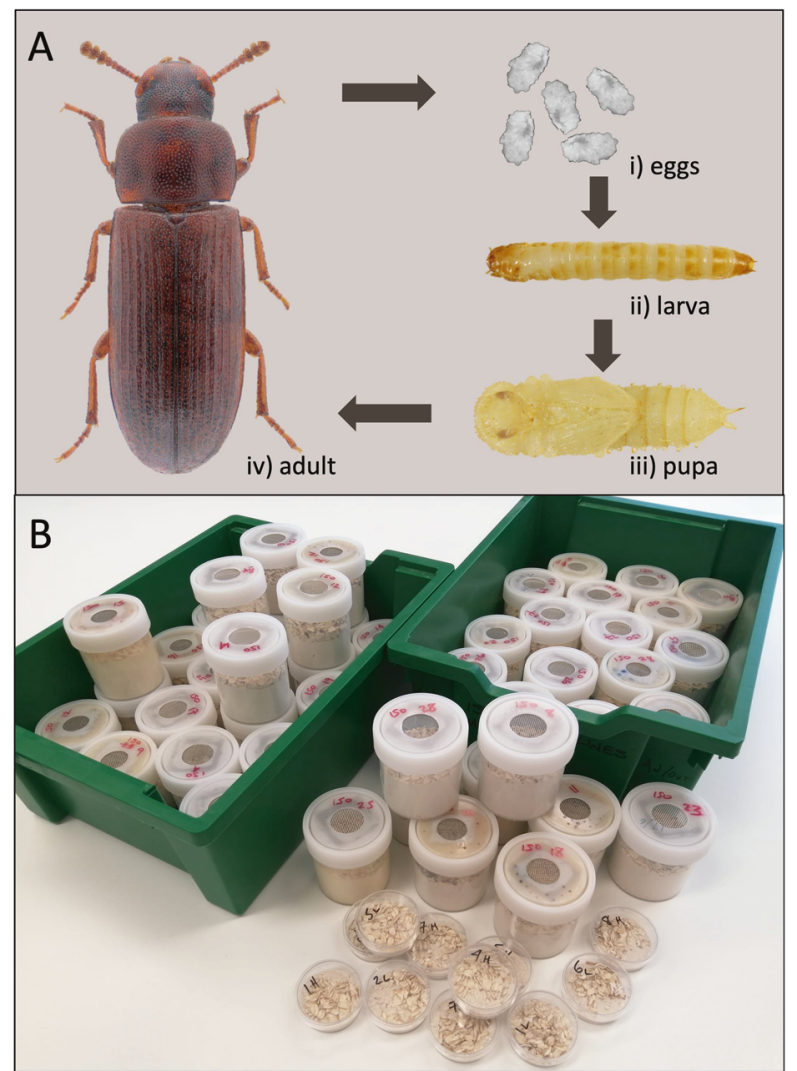

Fig. 2 Tribolium life history and husbandry. A Tribolium castaneum life stages (compiled from photographs by Udo Schmidt (adult), John Obermeyer (egg), and from Khan et al. 2016). B Experimental Tribolium populations housed in $250 \mathrm{ml}$ screw-top containers (top) and $50 \mathrm{~mm}$ Petri dishes, capable of supporting $\sim 500$ and $\sim 100$ individuals respectively without significant density-dependent effects.

(Denell 2008; Adamski et al. 2019). Other fields where Tribolium are used, including parasitology, ecoimmunology, the evolutionary ecology of infectious disease and applied pest management, have relevance to the areas discussed, though we lacked the space to include them here (e.g., Kerstes and Martin 2014; Perkin and Oppert 2019; Eggert et al. 2015). Broad reviews of Tribolium as a model in ecology and evolution also exist but are several decades old (e.g., King and Dawson 1972; Mertz 1972; Sokoloff 1977) and much new research in this area has since emerged. We therefore aim to demonstrate that the Tribolium literature testifies to the model's applicability across ecological and evolutionary fields and levels of biological organisation. We break the review down into conceptual areas, focusing on: (1) population dynamics, (2) reproduction and sexual selection, (3) population and quantitative genetics, and (4) behavioural ecology, ecophysiology and life-history evolution. We also discuss implications of Tribolium research findings for the broader ecological and evolutionary community, and suggest some ways in which
Box 1. Tribolium ecology and experimental tractability

Many aspects of Tribolium ecology make them well suited as experimental organisms:

- The Tribolium environment is also the food medium: a dry mix of fine particulates that is easily prepared and readily stored. Homogeneity within this medium eliminates micro-climatic and nutritional variation within and between replicate populations, allowing tight environmental control of both temperature and humidity, the latter being important in reducing the invasion of fungal pathogens.

- Owing to Tribolium's long human-commensal history ( 70,000 generations), the laboratory medium also has the advantage of very closely approximating its semi-wild habitat in food-storage facilities, allowing a lab environment that is less abstracted than that in other insect models.

- Egg-to-adult development is completed in $\sim 30$ days (at $30^{\circ} \mathrm{C}$ ), with roughly 3,20 and 4 days spent as egg, larva and pupa, respectively. Husbandry is therefore less tightly time constrained compared with faster-developing species, allowing more flexibility to generate high replicate numbers.

- Adults are small $(\sim 4 \mathrm{~mm})$ but dark in colour and easily distinguished from the medium. All stages, including eggs can be separated from the medium by simple sieving for counting or other experimental manipulations.

- Individuals are physically and behaviourally robust to handling, without the need for anaesthetisation, allowing methods such as paint-marking of individuals for later identification.

- The sexes can be distinguished in adults by the presence of a gland on the forelimbs of males, which is absent in females. Pre-reproductive individuals are most easily sexed as pupae, by their differential genital morphology, allowing single-sex cohorts or virgins to be isolated for breeding and mating studies.

- Though able to fly, individuals display very limited motivation to do so in the laboratory, making containment simple relative to insects that fly. Under specific conditions, however, flight behaviour can be induced in Tribolium.

- Tribolium mate and breed readily and promiscuously in the lab as pairs or groups, enabling manipulation of mating pattern, high levels of success in specific breeding crosses, and good opportunities for the recording of reproductive behaviour. 
this system can continue to enhance ecological and evolutionary research. We hope that this review will be valuable both to those within the Tribolium community, by providing context to the often highly specialised focus of individual research groups, and to a broader readership, by synthesising the significant contributions made to ecological and evolutionary science by this often-overlooked model species.

\section{Population dynamics}

The value of the Tribolium system in answering questions in population biology was recognised early in the twentieth century (Chapman 1918; Park 1934), and the system is well known for its contribution to this field. Here we break this research down into that covering (1) colonisation dynamics, (2) drivers of population size and regulation, and (3) competition. We focus on the empirical literature, but it is worth noting that Tribolium experiments have contributed to a large body of important mathematical modelling work aiming to predict population dynamics (Mertz 1972; reviewed in Costantino et al. 2005).

\section{Colonisation and spread}

Colonisation events are necessarily rare and therefore difficult to observe in nature, despite their importance. Lab models give us the opportunity to study and replicate events that determine the genetic and phenotypic make-up of contemporary populations. Tribolium life history is characterised by repeated episodes of dispersal and colonisation (Dawson 1977), making it an ideal system in which to investigate these processes in the laboratory. For instance, while it is well understood that the size and frequency of colonisation events are positively correlated with colonisation success (Lockwood et al. 2005), the role of genetic and demographic processes in underpinning this relationship is less clear. Tribolium experiments have shown that both the frequency and size of introductions affect the likelihood of establishment, with some evidence that the former may be more important (Koontz et al. 2018). Further, by manipulating levels of genetic diversity within colonising populations, an elegant set of Tribolium experiments have shown that demographic and genetic processes have independent roles in determining colonisation success, by affecting initial establishment success and subsequent population growth respectively (Szúcs et al. 2014; Szúcs and Melbourne et al. 2017). Similar experiments have shown that the colonising individuals' relative fitness in the new environment is as important as the number of colonisers (Vahsen et al. 2018), and that this affects population dynamics for many generations post-colonisation (Van Allen and Rudolf 2013).
Analysing the factors that underpin initial rates of population growth has also been a major aim of Tribolium research. It was in analysing Tribolium data that W.C. Allee formulated the theory that has become known as the 'Allee effect', an optimum density for initial population growth (Allee 1931; Park 1932), whereby at small population sizes mean individual fitness is reduced (Stephens et al. 1999). The rate of population growth has also been quantified across a range of environmental factors, including food quality and composition (e.g., Wong and Lee 2011), as well as life history parameters such as development time, with populations of fast-developing individuals able to grow more quickly than those in which individuals develop more slowly (Soliman 1972).

Tribolium is also well suited to the study of range expansion under a laboratory setting, using replicated populations within arrays of connected habitat patches. With such methods it has been shown that neutral stochastic processes are highly important in range expansion (WeissLehman et al. 2019), with endogenous variation leading to highly unpredictable rates of spread (Melbourne and Hastings 2009). By experimentally constraining evolution, this work has shown that adaptation also plays a key role during expansion and the early stages of colonisation (e.g. Szúcs et al. 2017), though subsequent gene flow may be required into small populations to mitigate drift load which may hinder adaptation (Stewart et al. 2017). Addressing this same issue from a conservation perspective, experimental tests of both demographic and genetic rescue have shown that these interventions can reduce extinction risk and have additive effects (Hufbauer et al. 2015).

\section{Population size and regulation}

A large body of experimental research has used Tribolium populations to determine the drivers of equilibrium population size and dynamics. Early Tribolium work showed that equilibrium population size is mediated by habitat volume (Chapman 1928). Tribolium researchers have since utilised the system to investigate questions regarding effective population size, including its response to population properties such as initial density (Wade 1980a) and its relationship to census population size (Pray et al. 1996).

Studies that have paired modelling approaches with Tribolium population biology experiments have added greatly to our understanding of population dynamic phenomena, directly linking theory to the behaviour of real populations (reviewed in Cushing et al. 2002; Costantino et al. 2005). Demographic parameters, predicted by models to lead to chaotic dynamics, were applied experimentally to Tribolium populations, exposing chaotic dynamics that could be reliably disrupted by minor intervention (Costantino et al. 1995, 1997; Desharnais et al. 2001). Comparing 
Tribolium population dynamic data to model predictions has further revealed influences of stochastic processes in the behaviour of populations, as well as identifying lattice effects (dynamics arising due to the discrete nature of individual organisms, e.g., Henson et al. 2001; King et al. 2004) and accounting for the ecological synchrony between separate populations (Desharnais et al. 2018).

Tribolium populations self-regulate via complex interactions of density-dependent effects on reproductive, developmental, dispersive and cannibalistic behaviours (King and Dawson 1972). Chemical secretions (see 'lifehistory' section, below) accumulate in the medium in proportion to time and density in a process known as "conditioning', and these secretions are used by the beetles as indicators of demographic parameters, such as population density (El-Desouky et al. 2018). Much of the work on this area was done in the early-mid nineteenth century and is well covered by King and Dawson (1972). Oviposition is suppressed by conditioning of the medium and increased by egg cannibalism (Sonleitner and Gutherie 1991). Recent work has shown that females evaluate current and future competitive conditions when making oviposition decisions (Halliday et al. 2019). Larval development is slowed by increasing larval and adult density (Park et al. 1939; Janus 1989). Higher density during development also has indirect negative effects on future reproductive success through reduced body weight (Assie et al. 2008). Dispersal increases with density (Ziegler 1978) and there is evidence that the genetic bases of dispersal and the reduction of oviposition in response to conditioning are linked (Lavie and Ritte 1980, see also 'Life history' below). Density-dependent processes in Tribolium are complex and act differentially on the sexes (Ellen et al. 2016), interact with food quality (patterns of density-dependent habitat selection depend on the foodstuffs used, Halliday et al. 2019) and weaken with deviation from thermal optimum (Halliday and BlouinDemers 2018).

Cannibalism is consistently shown to be core to many aspects of the Tribolium system, including population regulation. The degree of cannibalism increases with density until a point at which the predatory individuals become satiated (Park et al. 1965). Adult cannibalism of pupae is most effective at controlling adult numbers (Young 1970), while more nutritional benefit is gained from egg-eating (Alabi et al. 2008). Females are more voracious than males, and there is no reduction in cannibalism with increasingly conditioned medium (Flinn and Campbell 2012). The extra nutrition gained from cannibalism is able to compensate for the negative effects of high density (Mertz and Robertson 1970), and to facilitate colonisation of marginal nutritional habitat (Via 1999). Populations differ in their cannibalism rates, and these differences appear stable over many tens of generations; this may be because differences in cannibalism confer no selective advantage, or perhaps because populations can occupy different peaks on the selective landscape (Stevens 1989). Kin-selection may provide a mechanism for changes in cannibalism, as reduced rates of cannibalism between certain life stages have been observed within groups of highly related individuals (Wade 1980b).

Cannibalistic behaviour creates the periodic cycles in age-structure that characterise Tribolium populations (Costantino and Desharnais 1991) and, by manipulating population conditions, cycles can be altered or interrupted. When cannibalism is negated, by housing life stages separately, cycles disappear (Benoit 1998) and if populations are unconfined, allowing emigration, generations become non-overlapping (Ziegler 1972). These cycling phenomena are another area in which Tribolium has fostered close ties between theoretical and population biologists, by providing a convenient system in which to test theories of population dynamics, such as how environmental fluctuation affects population cycling (Reuman et al. 2008).

\section{Competition}

Much of the reputation of the Tribolium system is founded on the two-species competition experiments of Thomas Park and his collaborators and their indeterminate outcomes, which helped draw attention to the role of stochastic processes in ecology (Park et al. 1964). Briefly, using experimental populations containing both $T$. confusum and T. castaneum it has been shown that (i) one species is almost always driven to extinction; (ii) the 'winning species' cannot be predicted by the relative performance of each species cultured alone in the focal environment; (iii) outcomes can be indeterminate under certain conditions, whereby the 'winner' is not the same in all replicates; (iv) there was no evidence for an elevated 'win rate' of populations which had won in previous experiments, suggesting that competitive ability cannot be selected on (Park and Lloyd 1955). These results spawned much work trying to account for indeterminate outcomes, including mathematical modelling (e.g., Leslie 1962). Following this early work, competition experiments in Tribolium have shown that demography may be more important than genetics in determining competitive outcomes in this system (Mertz et al. 1976), although inbreeding depression can cause a loss of competitive ability at low founding size (Craig and Mertz 1994). Further, a wide range of external variables have been shown to affect competition dynamics, including reduced competitive ability resulting from parasite infection and/or low natal habitat quality, and deviation from the thermal optimum (e.g., Yan et al. 1998; Van Allen and Rudolf 2015). 


\section{Reproduction and sexual selection}

One of the most fundamental life processes is reproduction, yet much is still unknown about the origin and maintenance of sex, and the evolutionary forces that maintain the diversity of reproductive phenotypes observed in nature (Williams 1975). To address these, and related questions has been a rich area of Tribolium research. Indeed, T. castaneum was used in one of the first ever sperm competition and fertilisation precedence experiments (Schlager 1960). Previous broad reviews have identified ways by which females may influence paternity during and following mating, including: inhibiting sperm transfer; altering remating behaviour; controlling timing of spermatophore ejection (Pai and Bernasconi 2008; Fedina and Lewis 2008). These reviews also cover the male traits shown to affect paternity share in the many studies of sperm precedence conducted on Tribolium. We will therefore focus on subsequent advances in these areas.

Experimental studies have provided varied insights into the evolution and ecology of mating behaviour. Recent work on pre-copulatory behaviour has shown that females exhibit a preference for non-stressed males (McNemee and Marshall 2018) and that homosexual behaviour, which is quite common in T. castaneum, is dependent on the social environment and likely occurs due to inaccurate mate choice (Martin et al. 2015; Sales et al. 2018). Postcopulatory reproductive processes are also an important area of research, and there is much potential to track the dynamics of sperm behaviour and male-male interactions within the female tract in vivo. Advances in fluorescent tagging of sperm have made it possible to visualise sperm fate following natural matings and their movement through the tract to the fertilisation set (Droge-Young et al. 2016), and molecular methods have facilitated the study of seminal fluid proteins (South et al. 2011).

Many aspects of reproduction appear to be environment dependent, with factors such as nutrition, temperature, conditioning of medium and parasite presence shown to alter mating dynamics and reproductive fitness, both individually and in combination (Grazer et al. 2014; Khan et al. 2018; Sales et al. 2018; Vasudeva et al. 2019). Further, reproductive fitness has been shown to trade off with intrinsic factors such as walking ability (Matsumura et al. 2019) but can be enhanced by others, such as pesticide resistance (Arnaud et al. 2005). Phenotypic plasticity and genotype-by environment interactions also play an important role in determining levels of sexual conflict and adaptability (Lewis et al. 2012; Holman and Jacomb 2017).

Tribolium experiments have been used to address fundamental questions about the 'sex paradox', sexual selection and the origin of mating behaviours (Dunbrack et al. 1995). Key to these studies has been the experimental manipulation of sex ratios and mating patterns over one or multiple generations, thereby applying different sexual selection pressures, and then measuring the consequences. Using such approaches, it has been shown that levels of promiscuity increase following genetic bottlenecks, and therefore that promiscuity may provide a mechanism for avoiding genetic incompatibility (Michalczyk et al. 2011). Using long-term sexual selection lines and experimental inbreeding, Tribolium experiments demonstrated that sexual selection may buffer populations against extinction through purging of mutation load (Lumley et al. 2015). However, subsequent studies using alternative approaches to examine the relationship between sexual selection and mutation load have found no purging effects (e.g. Prokop et al. 2019). A population history (up to ten years) of experimentally applied, strong sexual selection has also been shown to improve the competitive ability of males and their sperm, and drive sperm morphology evolution (Michalczyk et al. 2011; Demont et al. 2014; Godwin et al. 2017), increase conspecific population invasion success (Godwin et al. 2018), enable population resilience to the extinction vortex (Godwin et al. 2020), and increase the rate of pesticide resistance evolution (Jacomb et al. 2016).

\section{Population and quantitative genetics}

Laboratory insect models have been instrumental in developing our understanding of population genetic theory, from the tracking of inversions in populations (Wright and Dobzhansky 1946) to the discovery of genetic markers (Lewontin and Hubby 1966). Though relatively understudied in comparison to Drosophila, many of the same features of Tribolium that made it originally attractive to those studying population dynamics, also make it suitable as a lens through which to view evolution in experimental populations from a genetic perspective. Since Park's competition experiments first drew the attention of geneticists towards the Tribolium system, genetic investigations have formed an important branch of its study (King and Dawson 1972). Genetic work on Tribolium spans levels of organisation, covering everything from the relationship of genotype to phenotype, through to interspecific reproductive isolation.

\section{Artificial selection and experimental evolution}

Early studies of adaptive evolution in Tribolium were based on observing phenotypic changes over generations, revealing that changes (in traits such as development time or pupal weight) can arise due to variation in productivity and cannibalism (Sokal and Sonleitner 1968; King and Dawson 1972). Similar, approaches have been used to show that the 
spread of a selfish genetic element through a population is proportional to the strength of its effect (Wade and Beeman 1994), and that pesticide-resistant genotypes can have increased fitness, even in the absence of pesticides (Haubruge and Arnaud 2001).

The majority of experimental studies of adaptive evolution have directly manipulated the strength of selection. Selection can be artificially applied, with those individuals who will seed the next generation being chosen by the researcher based on a given trait. Alternatively, experimental evolution can be used, where natural selection is allowed to act within populations subjected to a treatment. These techniques enable, amongst other things, the study of the relationship of genotype to phenotype. Provided that the strength of selection is known, trait heritability can be inferred from the response to selection. Alternatively, crosses between individuals of different phenotypes can reveal the genetic basis of traits. In these ways, it has been shown that traits such as pupal and adult weight are highly heritable in Tribolium (Wade et al. 1996). Some have moderate heritability, such as larval weight, development time and walking distance (Yamada 1974; Matsumura and Miyatake 2015). While some, like fecundity and deathfeigning duration, respond only weakly to artificial selection (Orozco and Bell 1974; Miyatake et al. 2004).

Response to selection has been shown not only in terms of the focal trait, but also in associated traits. For example, weight metrics show correlated responses to selection across life stages (Yamada 1974) and populations selected for short death-feigning duration also have short legs and lower walking motivation (Matsumura and Miyatake 2019). Lines selected for low dispersal propensity have greater longevity, poorer flight ability, are better competitors, develop more quickly and have longer generation times than dispersers (e.g., Zirkle et al. 1988). Some of these associations between traits can limit the response to selection (Irwin and Carter 2014), and attempts to break the correlations of pairs of traits through artificial selection have failed (Bell and Burris 1973; Tigreros and Lewis 2011).

Wright's shifting balance theory (Wright 1932) suggests that population structure may also influence response to selection, although there is limited evidence that this process plays an important role in nature (Coyne et al. 2000). Tribolium studies have applied artificial selection within sub-divide-and-merge population structures to test predictions of shifting balance theory (see Wade and Goodnight 1998). However, large panmictic populations have been found to respond better to selection for pupal weight than sub-divided, periodically mixing ones (Katz and Enfield 1977) and no difference in response was found using a similar design to select for offspring number (Schamber and Muir 2001). Further, it has been suggested that these experiments do not capture the complexity of the shifting balance process, and that doing so experimentally may not be possible (Coyne et al. 2000).

In addition to studying adaptation, Tribolium experiments have been used to understand the causes and consequences of stochastic processes such as mutation and drift in evolution (e.g., Rich et al. 1979). Inbreeding depression has been studied in detail in Tribolium, and inbreeding has been shown to have negative effects on a range of traits, including productivity and viability (López-Fanjul and Jódar 1977). Susceptibility to inbreeding depression can vary between populations and affect suites of traits within populations (Pray and Goodnight 1995; Pray 1997). Inbreeding has negative consequences for population growth and response to selection (McCauley and Wade 1981; Wade et al. 1996). However, the fitness consequences of inbreeding may only be realised in certain environments (subject to genotype-by-environment interactions arising under inbreeding), and may differ between sexes (Pray et al. 1994). The above studies generated inbreeding through enforced sib-sib matings, however more 'realistic' approaches have also been utilised. For example, by reducing population size but allowing free matings, bottleneck scenarios can be simulated, these have shown that subsequent stress following a bottleneck can reveal inbreeding severity, even after population size has recovered (Franklin and Siewerdt 2011).

\section{Divergence and speciation}

Genetic differentiation has been quantified empirically between wild Tribolium populations (Drury et al. 2009; McCulloch et al. 2019) and between lab populations of varying geographic origin (Yamauchi et al. 2018). While results conflict between studies, it is clear that at least some genetic structure exists within Tribolium species. Although there has been limited research into the drivers of population divergence, there is a substantial body of experimental research examining its consequences. Female $T$. castaneum have been shown to increase egg-laying rates when mated to inter-population males, suggesting potential inbreeding avoidance (Attia and Tregenza 2004). On the other hand, when the sperm of males from different populations compete for fertilisations, 'home' males can be seen to have an advantage, indicative of partial reproductive isolation (Pai and Yan 2002). Other inter-population crosses can result in perpetually immature larvae (Drury et al. 2011), and show genetic incompatibilities in $T$. castaneum that provide support for the Haldane's rule (Demuth and Wade 2007). Partial reproductive isolation through mate choice has also been observed between populations of $T$. confusum (Wade et al. 1995).

Moving beyond populations, species across the Tribolium genus display a range of divergence times, making 
them useful for studies of reproductive isolation at the species level. Between $T$. castaneum and $T$. confusum, reproductive isolation is incomplete (Shen et al. 2016), while between $T$. castaneum and T. freemani, hybrids are sterile (Wade and Johnson 1994). Interspecific crosses have therefore been used to study questions related to speciation, showing for instance that significant post-copulatory prezygotic isolation can arise through asymmetric sperm precedence under interspecific male competition (Robinson et al. 1994). Crosses between T. castaneum and T. freemani have also shown that the degree to which skewed sex ratios and male deformity manifest in the F1 generation varies with the geographic origin of the T. castaneum strain used, even at relatively local scales (Wade et al. 1997).

The wide range of geographic and genetic distances between the species of Tribolium, means that the group constitutes an excellent system for comparative genomic studies seeking to understand the drivers and consequences of speciation (Brown et al. 2009), this will likely be a rich area of future study. Another area for expansion in Tribolium research is population genomics: the attributes that have seen the system used in population studies in the past, along with its emerging ability to generate high quality genomic data, are suited to combine in the study of genomic responses to selection. This could take the form of 'evolve and resequence' approaches that have so far struggled to make it beyond Drosophila (Schlötterer et al. 2015).

\section{Behavioural ecology and life history}

Research on Tribolium began with studies of populations, but soon branched out to include the individual-level lifehistory traits that underlie the dynamics of populations, often in order to correctly parameterise mathematical models. Today Tribolium is a model for studying lifehistory parameters of invertebrates in its own right. Ongoing life-history studies in Tribolium can mostly be divided into those concerned with dispersal, movement and habitat selection; responses to environmental stress and diet; and studies of chemical biology and ageing.

\section{Dispersal, movement and habitat selection}

The study of why individuals disperse, what biological and environmental factors drive this, and the population-level consequences of this process are important areas in evolutionary ecology (Bowler and Benton 2005). Laboratory insect models offer a useful opportunity to study dispersal, as individuals can be tracked, the process of dispersal can be measured in a controlled and repeatable way, phenotypes associated with dispersal can be artificially selected, and the consequences of dispersal measured. Tribolium offers a particularly useful model in this respect, as it has two modes of dispersal (walking and flying), and is characterised by a life history that likely requires dispersal between patchy habitats (Dawson 1977). As a result, Tribolium has been widely used to study a broad range of questions about the evolutionary drivers and ecological consequences of dispersal.

Like many areas of Tribolium research, work on dispersal began in the mid twentieth century, but has seen a modern renaissance. Tribolium flight is rare, and early work focused on movement by walking, defining dispersal as the tendency of adults to leave a patch of habitat within an experimental apparatus composing two connected habitat chambers (Prus 1963; reviewed in King and Dawson 1972). Variations on this set-up over many years have shown dispersal to be dependent on a complex of factors, principally an interaction between density (ZromskaRudzka 1966) and age (see Ziegler 1976; Gurdasani et al. 2018), altered by population-age and relatedness structure (Ziegler 1978; Jasieński et al. 1988), food availability (Ziegler 1977), as well as the natal environment of a focal individual or a threshold proportion of its neighbours (Van Allen and Bhavsar 2014; Endriss et al. 2019). Adult dispersal tendency appears to have a strong genetic basis (Ritte and Agur 1977), but this tendency is not conserved within individuals between pre- and post-metamorphosis (Arnold et al. 2016). Tendency to disperse is more highly correlated with leg length than metabolic rate, indicating that dispersal phenotypes depend more on morphological than physiological traits in adults (Arnold et al. 2017). Dispersal rate and sensitivity of dispersal responses to age and environment are greater in $T$. castaneum than $T$. confusum, consistent with the former being a primary coloniser, following a more r-type strategy than that adopted by the latter (Ziegler 1976).

The last decade has seen significant attention paid to the study of flight behaviour of $T$. castaneum, with the influence of biotic and abiotic factors on flight responses being investigated in laboratory, wild and wild-caught populations. Relative humidity does not appear important, while wind speed and direction, temperature, light, resource provision, and quality, age and mating status have all been seen to alter flight initiation and/or duration (e.g., Drury et al. 2016; Gurdasani et al. 2019). Flight patterns appear to be crepuscular and show seasonality (Daglish et al. 2017; Rafter et al. 2019), though this pattern varies with latitude (Rajan et al. 2018). Consensus on the effect of sex on flight remains elusive, as the results of these studies do not agree on whether flight behaviour differs between males and females.

Movement in relation to habitat selection by different life stages has also been studied in Tribolium, which can occur either by walking on the surface of the medium, or 
tunnelling through it (Hagstrum and Smittle 1980). Larvae seeking pupation sites tend to move deeper into the medium, seeking warmth and low population density, even when this means using poor quality habitat (King and Dawson 1972; Mayes and Englert 1984; Janus 1989). Adults move in response to biotic factors, avoiding high density areas and highly conditioned media, and alter their behaviour according to their reproductive status (Naylor 1965; Wexler et al. 2017). Adult movement behaviour can also vary in response to abiotic factors, including temperature, humidity and habitat structure (Campbell and Hagstrum 2002; e.g., Halliday and Blouin-Demers 2017). Studies investigating the distribution of adults within a fodder mass have shown that fine-scale spatial and temporal structure exists, and that individual variation in patch exploitation can serve to maximise individual fitness (Surtees 1963; Campbell and Runnion 2003). This variation in movement behaviour in response to resource availability may differ when flying as opposed to walking, and between wild and laboratory populations (Ahmad et al. 2013; Ahmad et al. 2013).

\section{Other life-history features}

Tribolium represents a good model for studying the effects of stress due to the ease of replicability, and as a model that has relatively few ethical issues surrounding its use. Stress, in the form of starvation, heat or cold shock, or combinations thereof (Shostak et al. 2015), has been experimentally applied to show negative effects on reproductive output and behaviour, movement patterns, and immune response (Sbilordo and Gräzer 2011; Eggert et al. 2015; Wexler and Scharf 2017). Alternatively, effects of tolerance to stress can be the response variable, and this has been used to show that the ability to tolerate stress is affected by a range of factors including parental age (Halle et al. 2015), thermal acclimation regime (Izadi et al. 2019) and rearing conditions (Scharf et al. 2015). Later-life effects of natal/juvenile stress have also been shown in Tribolium, with the natal environment affecting adult dispersal (Van Allen and Bhavsar 2014), competitive dynamics (Van Allen and Rudolf 2015), productivity and rates of cannibalism (Boyer 1976).

Tribolium excrete a range of chemicals into their environment, some of which are aggregation pheromones (mainly 4,8 dimethyldecanal, Suzuki 1980), whereas others are a defence against predators and microorganisms whilst playing an important role in population dynamics as indicators of population density (Arnaud et al. 2000). The chemicals used as pheromones differ across the genus (Arnaud et al. 2002), and are produced predominantly by males, eliciting the strongest responses from females (Stevenson et al. 2017). Diet alters the chemical composition of secretions, but may not alter their efficacy (Ming and Lewis 2010). Defensive compounds such as benzoquinones have antimicrobial properties (Prendeville and Stevens 2002) and show genetically controlled differential production across individuals (Yezerski et al. 2004). Due to the shared benefit of their action through density regulation, and the individual costs associated with their production, this can represent a social dilemma (Gokhale et al. 2017). The distinction between these two classes of secretions is not clear, with benzoquinones also shown to possess pheromone-like attractive properties (Verheggen et al. 2007). Understanding Tribolium chemobiology represents a fascinating future challenge, given the potential of secretions to influence individual, population and interspecies processes.

Considering its role as a pest, there has been much interest in the ability of Tribolium to utilise different food resources and the effect that these have on its life history. Early authors list a wide range of products on which Tribolium has been found, including flours of many grains, peas, beans, nuts, chocolate and several spices (e.g., Chittenden 1896). Grain preference was among the first tests performed by Chapman, the man credited with pioneering the use of Tribolium for experimental study, who found a preference for wheat flour, and an inability to feed on whole grains (Chapman 1918; Park 1934). Very many studies of responses to diet and diet quality in Tribolium have since been published, which show that natural or artificial diets result in large effects on a broad range of fitness parameters (e.g., Sinha 1966; Sokoloff et al. 1966; Wong and Lee 2011).

Finally, there is a limited body of research on ageing in Tribolium. T. confusum was the organism in which exposure to radiation was first shown to increase longevity (Davey 1917); this work was subsequently expanded on and replicated widely among insects (Ducoff 1986; Calabrese 2013). However, recent decades have seen Tribolium superseded as an invertebrate model of ageing by relatively short-lived alternatives in Drosophila, C. elegans and yeast (Kennedy 2008). Nonetheless, age-related changes have been shown in individual-level morphological, physiological, biochemical, behavioural and pathological traits (Soliman 1987). Ageing research in Tribolium has generated important insights into the link between development and ageing and their genetic basis and the evolution of senescence (Soliman and Lints 1975; Mertz 1975). Some more recent work has highlighted parental-age effects on development and stress tolerance (Halle et al. 2015) and a decline in metrics of movement with increasing age (Wexler et al. 2016). As a relatively long-lived arthropod model (adults can live for up to 4 years, Good 1936) Tribolium may have utility for understanding ageing in slower-senescing animals such as vertebrates. 


\section{Future directions and conclusions}

We have highlighted some of the broad range of fields in which Tribolium has been successfully used as a research model. However, we believe that there is still much untapped potential from this organism for addressing several research areas, particularly the expansion of historically productive Tribolium fields in combination with genomic data. Studies of divergence can continue to exploit the genus' diversity and mating ecology, in combination with genomic techniques, to probe deeper into the process of species formation. Population dynamic and artificial selection responses can be investigated at the level of the entire genome, expanding the complexity of our understanding. Pest management can employ genomic information to increase the efficacy and specificity of its techniques, minimising the collateral damage while maximising benefits.

Importantly, Tribolium research can also incorporate work on climate change, which represents an enormous threat to biodiversity, with insects likely to be severely affected due to their short life cycles and temperature sensitivity (Bale et al. 2002). There is great scope for Tribolium as a model in which to study the effects of climate change on insects, for example by studying their physiological, ecological and evolutionary responses to experimental evolution under increased temperature. Many of the characteristics lending research utility to Tribolium (Box 1) also make it highly suitable as a research-led teaching resource (Hoste 1968), a role in which we feel it has been underutilised in the past.

Tribolium beetles possess many attributes that have made them a desirable study organism through a long history and breadth of application. They have contributed to many important past discoveries, and continue to be employed in addressing fundamental questions across fields in evolution and ecology. The utility of Tribolium spans levels of organisation, and a great responsiveness to genetic manipulation (Brown et al. 2009) promises to extend their relevance far into the genomic age. The ever-growing research infrastructure, and ability to integrate knowledge from across fields, makes Tribolium a valuable model system to complement the established invertebrate models of Drosophila and C. elegans.

Acknowledgements Thanks go to Mark McMullan, David Richardson and three anonymous reviewers for valuable comments that helped improve the manuscript. This research was funded by a BBSRC NRP DTP funded PhD studentship to MDP and a BBSRC Future Leader fellowship to LGS (BB/N011759/1).

\section{Compliance with ethical standards}

Conflict of interest The authors declare no competing interests.
Publisher's note Springer Nature remains neutral with regard to jurisdictional claims in published maps and institutional affiliations.

Open Access This article is licensed under a Creative Commons Attribution 4.0 International License, which permits use, sharing, adaptation, distribution and reproduction in any medium or format, as long as you give appropriate credit to the original author(s) and the source, provide a link to the Creative Commons license, and indicate if changes were made. The images or other third party material in this article are included in the article's Creative Commons license, unless indicated otherwise in a credit line to the material. If material is not included in the article's Creative Commons license and your intended use is not permitted by statutory regulation or exceeds the permitted use, you will need to obtain permission directly from the copyright holder. To view a copy of this license, visit http://creativecommons. org/licenses/by/4.0/.

\section{References}

Adamski Z, Bufo SA, Chowański S, Falabella P, Lubawy J, Marciniak $\mathrm{P}$ et al. (2019) Beetles as model organisms in physiological, biomedical and environmental studies-a review. Front Physiol 10:319

Ahmad F, Daglish GJ, Ridley AW, Burrill PR, Walter GH (2013) Short-range resource location by Tribolium castaneum Herbst (Coleoptera: Tenebrionidae) demonstrates a strong preference for fungi associated with cotton seed. J Stored Prod Res 52:21-27

Ahmad F, Ridley AW, Daglish GJ, Burrill PR, Walter GH (2013) Response of Tribolium castaneum and Rhyzopertha dominica to various resources, near and far from grain storage. J Appl Entomol 137:773-781

Alabi T, Michaud JP, Arnaud L, Haubruge E (2008) A comparative study of cannibalism and predation in seven species of flour beetle. Ecol Entomol 33:716-726

Allee WC (1931) Animal aggregations: a study in general sociology. University of Chicago Press, Chicago

Andres A (1931) Catalogue of the Egyptian Tenebrionidae. Bull de la Société R Entomologique d'Egypte 15:74-125

Ankeny RA, Leonelli S (2011) What's so special about model organisms? Stud Hist Philos Sci B Stud Hist Philos Mod Phys 42:313-323

Arnaud L, Haubruge E, Gage MJG (2005) The malathion-specific resistance gene confers a sperm competition advantage in Tribolium castaneum. Funct Ecol 19:1032-1039

Arnaud L, Lognay G, Gaspar C, Haubruge E et al. (2000) Chemical communication in Tribolium castaneum (Coleoptera, Tenebrionidae): knowledge and perspectives. Bulletin OILB/SROP 23:195-209

Arnaud L, Lognay G, Verscheure M, Leenaers L, Gaspar C, Haubruge E (2002) Is dimethyldecanal a common aggregation pheromone of Tribolium flour beetles? J Chem Ecol 28:523-532

Arnold PA, Cassey P, White CR (2016) Maturity matters for movement and metabolic rate: trait dynamics across the early adult life of red flour beetles. Anim Behav 111:181-188

Arnold PA, Cassey P, White CR (2017) Functional traits in red flour beetles: the dispersal phenotype is associated with leg length but not body size nor metabolic rate. Funct Ecol 31:653-661

Assie LK, Brostaux Y, Haubruge E (2008) Density-dependent reproductive success in Tribolium castaneum (Herbst) (Coleoptera: Tenebrionidae). J Stored Prod Res 44:285-289

Attia FA, Tregenza T (2004) Divergence revealed by population crosses in the red flour beetle Tribolium castaneum. Evol Ecol Res 6:927-935 
Bale JS, Masters GJ, Hodkinson ID, Awmack C, Bezemer TM, Brown VK et al. (2002) Herbivory in global climate change research: direct effects of rising temperature on insect herbivores. Glob Chang Biol 8:1-16

Barr MM (2003) Super models. Physiol Genom 13:15-24

Bell AE, Burris MJ (1973) Simultaneous selection for two correlated traits in Tribolium. Genet Res 21:29-46

Bolker J (2012) Model organisms: there's more to life than rats and flies. Nature 491:31-33

Bowler DE, Benton TG (2005) Causes and consequences of animal dispersal strategies: relating individual behaviour to spatial dynamics. Biol Rev Camb Philos Soc 80:205-225

Boyer JF (1976) The effects of prior environments on Tribolium castaneum. J Anim Ecol 45:865-874

Brown SJ, Denell RE, Beeman RW (2003) Beetling around the genome. Genet Res 82:155-161

Brown SJ, Shippy TD, Miller S, Bolognesi R, Beeman RW, Lorenzen MD et al. (2009) The red flour beetle, Tribolium castaneum (Coleoptera): a model for studies of development and pest biology Cold Spring Harb Protoc 2009:db.emo126

Calabrese EJ (2013) Low doses of radiation can enhance insect lifespans. Biogerontology 14:365-381

Campbell JF, Hagstrum DW (2002) Patch exploitation by Tribolium castaneum: movement patterns, distribution, and oviposition. J Stored Prod Res 38:55-68

Campbell JF, Runnion C (2003) Patch exploitation by female red flour beetles, Tribolium castaneum. J Insect Sci 3:20

Chapman RN (1918) The confused flour beetle (Tribolum confusum, Duval)

Chapman RN (1928) The quantitative analysis of environmental factors. Ecology 9:111-122

Chittenden FH (1896) Some insects injurious to stored grain. U.S. Department of Agriculture, Washington

Costantino RF, Desharnais RA (1991) Population dynamics and the tribolium model: genetics and demography. Springer Science \& Business Media, New York

Costantino RF, Desharnais RA, Cushing JM, Dennis B, Henson SM, King AA (2005) Nonlinear stochastic population dynamics: the flour beetle Tribolium as an effective tool of discovery. Adv Ecol Res 37:101-141

Coyne JA, Barton NH, Turelli M (2000) Is Wright's shifting balance process important in evolution? Evolution 54:306-317

Costantino RF, Cushing JM, Dennis B, Desharnais RA (1995) Experimentally induced transitions in the dynamic behaviour of insect populations. Nature 375:227-230

Costantino RF, Desharnais RA, Cushing JM, Dennis B (1997) Chaotic Dynamics in an Insect Population. Science 275:389-391

Craig DM, Mertz DB (1994) Inbreeding effects on competition in Tribolium. Res Popul Ecol 36:251-254

Cushing JM, Costantino RF, Dennis B, Desharnais R, Henson SM (2002) Chaos in Ecology: Experimental Nonlinear Dynamics. Academic Press, San Diego CA

Daglish GJ, Ridley AW, Reid R, Walter GH (2017) Testing the consistency of spatio-temporal patterns of flight activity in the stored grain beetles Tribolium castaneum (Herbst) and Rhyzopertha dominica (F.). J Stored Prod Res 72:68-74

Davey WP (1917) The effect of X-rays on the length of life of Tribolium confusum. J Exp Zool 22:573-592

Dawson PS (1977) Life history strategy and evolutionary history of Tribolium flour beetles. Evolution 31:226-229

Demont M, Grazer VM, Michalczyk Ł, Millard AL (2014) Experimental removal of sexual selection reveals adaptations to polyandry in both sexes. Evol Biol 41:62-70

Demuth JP, Wade MJ (2007) Population differentiation in the beetle Tribolium castaneum. II. Haldane's rule and incipient speciation. Evolution 61:694-699
Denell R (2008) Establishment of Tribolium as a genetic model system and its early contributions to evo-devo. Genetics 180:1779-1786

Desharnais RA, Costantino RF, Cushing JM, Henson SM, Dennis B (2001) Chaos and population control of insect outbreaks. Ecol Lett 4:229-235

Desharnais RA, Reuman DC, Costantino RF, Cohen JE (2018) Temporal scale of environmental correlations affects ecological synchrony. Ecol Lett 21:1800-1811

Dönitz J, Schmitt-Engel C, Grossmann D, Gerischer L, Tech M, Schoppmeier M et al. (2015) iBeetle-Base: a database for RNAi phenotypes in the red flour beetle Tribolium castaneum. Nucleic Acids Res 43:D720-5

Droge-Young EM, Belote JM, Perez GS, Pitnick S (2016) Resolving mechanisms of short-term competitive fertilization success in the red flour beetle. J Insect Physiol 93-94:1-10

Drury DW, Jideonwo VN, Ehmke RC, Wade MJ (2011) An unusual barrier to gene flow: perpetually immature larvae from interpopulation crosses in the flour beetle, Tribolium castaneum. J Evol Biol 24:2678-2686

Drury DW, Siniard AL, Wade MJ (2009) Genetic differentiation among wild populations of Tribolium castaneum estimated using microsatellite markers. J Hered 100:732-741

Drury DW, Whitesell ME, Wade MJ (2016) The effects of temperature, relative humidity, light, and resource quality on flight initiation in the red flour beetle, Tribolium castaneum. Entomol Exp Appl 158:269-274

Ducoff HS (1986) Radiation and longevity enhancement in Tribolium. In: Collatz K-G, Sohal RS (eds) Insect aging: strategies and mechanisms. Springer Berlin Heidelberg, Berlin, Heidelberg, $p$ 73-89

Dunbrack RL, Coffin C, Howe R (1995) The cost of males and the paradox of sex - experimental investigation of the short-term competitive advantages of evoltion in sexual populations. Proc $\mathrm{R}$ Soc B-Biol Sci 262:45-49

Eggert H, Diddens-de Buhr MF, Kurtz J (2015) A temperature shock can lead to trans-generational immune priming in the red flour beetle Tribolium castaneum. Ecol Evol 5:1318-1326

El-Aziz SEA (2011) Control strategies of stored product pests. J Entomol 8:101-122

El-Desouky TA, Elbadawy SS, Hussain HBH, Hassan NA (2018) Impact of insect densities Tribolium castaneum on the benzoquinone secretions and aflatoxins levels in wheat flour during storage periods. Open Biotechnol J 12:104-111

Ellen ED, Peeters K, Verhoeven M, Gols R, Harvey JA, Wade MJ et al. (2016) Direct and indirect genetic effects in life-history traits of flour beetles (Tribolium castaneum): Indirect genetic effects in Tribolium. Evolution 70:207-217

Endriss SB, Vahsen ML, Bitume EV, Grey Monroe J, Turner KG, Norton AP et al. (2019) The importance of growing up: juvenile environment influences dispersal of individuals and their neighbours. Ecol Lett 22:45-55

Fedina TY, Lewis SM (2008) An integrative view of sexual selection in Tribolium flour beetles. Biol Rev Camb Philos Soc 83:151-171

Flinn PW, Campbell JF (2012) Effects of flour conditioning on cannibalism of $T$. castaneum eggs and pupae. Environ Entomol 41:1501-1504

Franklin AD, Siewerdt F (2011) Post-bottleneck inbreeding accumulation reduces fitness and adaptive potential in populations of Tribolium castaneum under environmental stress. Genomics and Quantitative. Genetics 2:19-30

Godwin JL, Lumley AJ, Michalczyk L, Martin OY, Gage MJG (2020) Mating patterns influence vulnerability to the extinction vortex. Global Change Biology 26:4226-4239

Godwin JL, Spurgin LG, Michalczyk Ł, Martin OY, Lumley AJ, Chapman T et al. (2018) Lineages evolved under stronger sexual 
selection show superior ability to invade conspecific competitor populations. Evol Lett 2:511-523

Godwin JL, Vasudeva R, Michalczyk Ł, Martin OY, Lumley AJ, Chapman T et al. (2017) Experimental evolution reveals that sperm competition intensity selects for longer, more costly sperm. Evol Lett 1:102-113

Gokhale CS, Traulsen A, Joop G (2017) Social dilemma in the external immune system of the red flour beetle? It is a matter of time. Ecol Evol 7:6758-6765

Good NE (1936) The flour beetles of the genus Tribolium. ageconsea rch.umn.edu

Grazer VM, Demont M, Michalczyk Ł, MJG Gage, Martin OY (2014) Environmental quality alters female costs and benefits of evolving under enforced monogamy. BMC Evol Biol 14:21

Gurdasani K, Rafter MA, Daglish GJ, Walter GH (2018) Characterising the variables associated with Tribolium castaneum adults that initiate flight in laboratory tests - generating predictions for the field. J Stored Prod Res 79:123-131

Gurdasani K, Rafter MA, Daglish GJ, Walter GH (2019) The dispersal flight of Tribolium castaneum - a field test of laboratory generated predictions. J Stored Prod Res 83:25-33

Hagstrum DW, Smittle BJ (1980) Age- and sex-specific tunneling rates of adult Tribolium castaneum. Ann Entomol Soc Am 73:11-13

Halle S, Nowizki A, Scharf I (2015) The consequences of parental age for development, body mass and resistance to stress in the red flour beetle. Biol J Linn Soc Lond 115:305-314

Halliday WD, Blouin-Demers G (2017) A test of the thermal coadaptation hypothesis with ultimate measures of fitness in flour beetles. J Therm Biol 69:206-212

Halliday WD, Blouin-Demers G (2018) Can temperature modify the strength of density-dependent habitat selection in ectotherms? A test with red flour beetles. J Zool 304:159-168

Halliday WD, Bourque C, Blouin-Demers G (2019) Food quality influences density-dependent fitness, but not always densitydependent habitat selection, in red flour beetles (Coleoptera: Tenebrionidae). Can Entomol 151:728-737

Halliday WD, Slevan-Tremblay I, Blouin-Demers G (2019) Do female red flour beetles assess both current and future competition during oviposition? J Insect Behav 32:181-187

Hartmann S, Frigg R (2005) Scientific models. In: Sarkar Sahotra (ed.) The philosophy of science: an encyclopedia, Vol. 2, Routledge, London

Haubruge E, Arnaud L (2001) Fitness consequences of malathionspecific resistance in red flour beetle (Coleoptera: Tenebrionidae) and selection for resistance in the absence of malathion. $\mathrm{J}$ Econ Entomol 94:552-557

Hedges SB (2002) The origin and evolution of model organisms. Nat Rev Genet 3:838-849

Henson SM, Costantino RF, Cushing JM, Desharnais RA, Dennis B, King AA (2001) Lattice effects observed in chaotic dynamics of experimental populations. Science 294:602-605

Herndon N, Shelton J, Gerischer L, Ioannidis P, Ninova M, Dönitz J et al. (2020) Enhanced genome assembly and a new official gene set for Tribolium castaneum. BMC Genom 21:47

Holman L, Jacomb F (2017) The effects of stress and sex on selection, genetic covariance, and the evolutionary response. J Evol Biol 30:1898-1909

Hoste R (1968) The Use of Tribolium beetles for class practical work in genetics. J Biol Educ 2:365-372

Hufbauer RA, Szúcs M, Kasyon E, Youngberg C, Koontz MJ, Richards C et al. (2015) Three types of rescue can avert extinction in a changing environment. Proc Natl Acad Sci USA 112:10557-10562

Irwin KK, Carter PA (2014) Artificial selection on larval growth curves in Tribolium: correlated responses and constraints. J Evol Biol 27:2069-2079
Izadi H, Mohammadzadeh M, Mehrabian M (2019) Cold tolerance of the Tribolium castaneum (Coleoptera: Tenebrionidae), under different thermal regimes: impact of cold acclimation. J Econ Entomol 112:1983-1988

Jacomb F, Marsh J, Holman L (2016) Sexual selection expedites the evolution of pesticide resistance. Evolution 70:2746-2751

Janus MC (1989) Phenotypic diversity of Tribolium confusum pupae in heterogeneous environments. Entomol Exp Appl 50:281-286

Jasieński M, Korzeniak U, Łomnicki A (1988) Ecology of kin and nonkin larval interactions in Tribolium beetles. Behav Ecol Sociobiol 22:277-284

Katz AJ, Enfield FD (1977) Response to selection for increased pupa weight in Tribolium castaneum as related to population structure*. Genet Res 30:237-246

Kennedy BK (2008) The genetics of ageing: insight from genomewide approaches in invertebrate model organisms. J Intern Med 263:142-152

Kerstes NAG, Martin OY (2014) Insect host-parasite coevolution in the light of experimental evolution. Insect Sci 21:401-414

Khan I, Prakash A, Agashe D (2016) Divergent immune priming responses across flour beetle life stages and populations. Ecol Evol 6:7847-7855

Khan I, Prakash A, Issar S, Umarani M, Sasidharan R, Masagalli JN et al. (2018) Female density-dependent chemical warfare underlies fitness effects of group sex ratio in flour beetles. Am Nat 191:306-317

Kim HS, Murphy T, Xia J, Caragea D, Park Y, Beeman RW et al. (2010) BeetleBase in 2010: revisions to provide comprehensive genomic information for Tribolium castaneum. Nucleic Acids Res 38:D437-42

King AA, Costantino RF, Cushing JM, Henson SM, Desharnais RA, Dennis B (2004) Anatomy of a chaotic attractor: Subtle modelpredicted patterns revealed in population data. P Natl Acad Sci USA 101:408-413

King CE, Dawson PS (1972) Population biology and the Tribolium model. Evol Biol 1972:5

Koontz MJ, Oldfather MF, Melbourne BA, Hufbauer RA (2018) Parsing propagule pressure: Number, not size, of introductions drives colonization success in a novel environment. Ecol Evol 8:8043-8054

Lavie B, Ritte U (1980) Correlated effects of the response to conditioned medium in the flour beetle, Tribolium castaneum. Res Popul Ecol 21:228-232

Leslie PH (1962) A stochastic model for two competing species of Tribolium and its application to some experimental data. Biometrika 49:1-25

Lewis SM, Tigreros N, Fedina T, Ming QL (2012) Genetic and nutritional effects on male traits and reproductive performance in Tribolium flour beetles. J Evol Biol 25:438-451

Lewontin RC, Hubby JL (1966) A molecular approach to the study of genic heterozygosity in natural populations. II. Amount of variation and degree of heterozygosity in natural populations of Drosophila pseudoobscura. Genetics 54:595-609

Lockwood JL, Cassey P, Blackburn T (2005) The role of propagule pressure in explaining species invasions. Trends Ecol Evol 20:223-228

López-Fanjul C, Jódar B (1977) The genetic properties of egg laying of virgin females of Tribolium castaneum. Heredity 39:251-258

Lumley AJ, Michalczyk Ł, Kitson JJN, Spurgin LG, Morrison CA, Godwin JL et al. (2015) Sexual selection protects against extinction. Nature 522:470-473

Martin CM, Kruse KC, Switzer PV (2015) Social experience affects same-sex pairing behavior in male red flour beetles (Tribolium castaneum Herbst). J Insect Behav 28:268-279

Matsumura K, Archer CR, Hosken DJ, Miyatake T (2019) Artificial selection on walking distance suggests a mobility-sperm competitiveness trade-off. Behav Ecol 
Matsumura K, Miyatake T (2015) Differences in attack avoidance and mating success between strains artificially selected for dispersal distance in Tribolium castaneum. PLoS ONE 10:e0127042

Matsumura K, Miyatake T (2019) Lines selected for different durations of tonic immobility have different leg lengths in the red flour beetle Tribolium castaneum. Behaviour 157:17-31

Mayes PA, Englert DC (1984) Interstrain differences for larval dispersal and egg cannibalism in the flour beetle, Tribolium castaneum. Can J Genet Cytol 26:420-424

McCauley DE, Wade MJ (1981) The populational effects of inbreeding in Tribolium. Heredity 46:59-67

McCulloch GA, Mohankumar S, Subramanian S, Rajan TS, Rahul C, Surendran R et al. (2019) Contrasting patterns of phylogeographic structuring in two key beetle pests of stored grain in India and Australia. J Pest Sci 92:1249-1259

McNemee R, Marshall J (2018) Temperature stressed males are less attractive to female red flour beetles. In: Proceeding of 3rd Entomology Undergraduate Research Poster Symposium. Kansas State University, Department of Entomology, Manhattan, KS

Melbourne BA, Hastings A (2009) Highly variable spread rates in replicated biological invasions: fundamental limits to predictability. Science 325:1536-1539

Mertz DB (1972) The Tribolium model and the mathematics of population growth. Annu Rev Ecol Syst 3:51-78

Mertz DB (1975) Senescent decline in flour beetle strains selected for early adult fitness. Physiol Zool 48:1-23

Mertz DB, Cawthon DA, Park T (1976) An experimental analysis of competitive indeterminacy in Tribolium. Proc Natl Acad Sci USA 73:1368-1372

Mertz DB, Robertson JR (1970) Some developmental consequences of handling, egg-eating, and population density for flour beetle larvae. Ecology 51:989-998

Michalczyk Ł, Millard AL, Martin OY, Lumley AJ, Emerson BC, Chapman $\mathrm{T}$ et al. (2011) Inbreeding promotes female promiscuity. Science 333:1739-1742

Ming Q-L, Lewis SM (2010) Pheromone production by male Tribolium castaneum (Coleoptera: Tenebrionidae) is influenced by diet quality. J Econ Entomol 103:1915-1919

Miyatake T, Katayama K, Takeda Y, Nakashima A, Sugita A, Mizumoto M (2004) Is death-feigning adaptive? Heritable variation in fitness difference of death-feigning behaviour. Proc R Soc B-Biol Sci 271:2293-2296

Müller B, Grossniklaus U (2010) Model organisms-a historical perspective. J Proteom 73:2054-2063

Naylor AF (1965) Dispersal responses of female flour beetles, Tribolium confusum, to presence of larvae. Ecology 46:341-343

Orozco F, Bell AE (1974) A genetic study of egg laying of Tribolium in optimal and stress environments. Can J Genet Cytol $16: 49-60$

Pai A, Bernasconi G (2008) Polyandry and female control: the red flour beetle Tribolium castaneum as a case study. J Exp Zool B Mol Dev Evol 310:148-159

Pai A, Yan G (2002) Female mate choice in relation to heterozygosity in Tribolium castaneum: female mate choice and heterozygosity. J Evol Biol 15:1076-1082

Park T (1932) Studies in population physiology: the relation of numbers to initial population growth in the flour beetle Tribolium confusum Duval. Ecology 13:172-181

Park T (1934) Observations on the general biology of the flour beetle, Tribolium confusum. Q Rev Biol 9:36-54

Park T (1962) Beetles, competition, and populations. Science 138:1369-1375

Park T, Leslie PH, Mertz DB (1964) Genetic strains and competition in populations of Tribolium. Physiol Zool 37:97-162

Park T, Lloyd M (1955) Natural selection and the outcome of competition. Am Nat 89:235-240
Park T, Mertz DB, Grodzinski W, Prus T (1965) Cannibalistic predation in populations of flour beetles. Physiol Zool 38:289-321

Park T, Miller EV, Lutherman CZ (1939) Studies in population physiology. IX. The effect of imago population density on the duration of the larval and pupal stages of Tribolium confusum Duval. Ecology 20:365-373

Perkin LC, Oppert B (2019) Gene expression in Tribolium castaneum life stages: Identifying a species-specific target for pest control applications. PeerJ 7:e6946

Pray LA (1997) The effect of inbreeding on population-level genetic correlations in the red flour beetle Tribolium castaneum. Evolution 51:614-619

Pray LA, Goodnight CJ (1995) Genetic variation in inbreeding depression in the red flour beetle Tribolium castaneum. Evolution 49:176-188

Pray LA, Goodnight CJ, Stevens L, Schwartz JM, Yan G (1996) The effect of population size on effective population size: an empirical study in the red flour beetle Tribolium castaneum. Genet Res 68:151-155

Pray LA, Schwartz JM, Goodnight CJ, Stevens L (1994) Environmental dependency of inbreeding depression: implications for conservation biology. Conserv Biol 8:562-568

Prendeville HR, Stevens L (2002) Microbe inhibition by Tribolium flour beetles varies with beetle species, strain, sex, and microbe group. J Chem Ecol 28:1183-1190

Prokop ZM, Hlebowicz K, Gaczorek TS, Antol WM, Martin OY, Gage MJG et al. (2019) No evidence for short-term purging benefits of sexual selection in inbred red flour beetle populations. J Zool 307:178-185

Prus T (1963) Search for methods to investigate mobility in Tribolium. Ecology 44:801-803

Rafter MA, Muralitharan V, Chandrasekaran S, Mohankumar S, Daglish GJ, Loganathan M et al. (2019) Behaviour in the presence of resource excess-flight of Tribolium castaneum around heavily-infested grain storage facilities. J Pest Sci 92:1227-1238

Rajan TS, Muralitharan V, Daglish GJ, Mohankumar S, Rafter MA, Chandrasekaran S et al. (2018) Flight of three major insect pests of stored grain in the monsoonal tropics of India, by latitude, season and habitat. J Stored Prod Res 76:43-50

Reuman DC, Costantino RF, Desharnais RA, Cohen JE (2008) Colour of environmental noise affects the nonlinear dynamics of cycling, stage-structured populations. Ecol Lett 11:820-830

Rich SS, Bell AE, Wilson SP (1979) Genetic drift in small populations of Tribolium. Evolution 33:579-584

Ritte U, Agur Z (1977) Variability for dispersal behavior in a wild population of Tribolium castaneum. Tribolium Inf Bull 20:122-131

Robinson T, Johnson NA, Wade MJ (1994) Postcopulatory, prezygotic isolation: intraspecific and interspecific sperm precedence in Tribolium spp., flour beetles. Heredity 73(Pt 2):155-159

Sales K, Trent T, Gardner J, Lumley AJ, Vasudeva R (2018) Experimental evolution with an insect model reveals that male homosexual behaviour occurs due to inaccurate mate choice. Anim Behav

Sales K, Vasudeva R, Dickinson ME, Godwin JL, Lumley AJ, Michalczyk $€$ et al. (2018) Experimental heatwaves compromise sperm function and cause transgenerational damage in a model insect. Nat Commun 9:4771

Sbilordo SH, Gräzer VM (2011) Impacts of starvation on male reproductive success in Tribolium castaneum. Evol Ecol Res 13:347-359

Schamber EM, Muir WM (2001) Wright's shifting balance theory of evolution in artificial breeding programmes: empirical testing using the model organism Tribolium castaneum. J Anim Breed Genet-Z Fur Tierz Und Zuchtungsbiologie 118:181-188 
Scharf I, Galkin N, Halle S (2015) Disentangling the consequences of growth temperature and adult acclimation temperature on starvation and thermal tolerance in the red flour beetle. Evol Biol 42:54-62

Schlager G (1960) Sperm Precedence in the Fertilization of Eggs in Tribolium castaneum. Ann Entomol Soc Am 53:557-560

Schlötterer C, Kofler R, Versace E, Tobler R, Franssen SU (2015) Combining experimental evolution with next-generation sequencing: a powerful tool to study adaptation from standing genetic variation. Heredity 114:431-440

Shen J-F, Cheng C, Ming Q-L (2016) Study on reproductive isolation between Tribolium castaneum and T. confusum. J Environ Entomol 3:508-513

Shostak AW, Van Buuren KG, Cook R (2015) Response of flour beetles to multiple stressors of parasitic (Hymenolepis diminuta), environmental (Diatomaceous Earth), and host (Reproduction) origin. J Parasitol 101:405-417

Sinha RN (1966) Development and mortality of Tribolium castaneum and T. confusum (Coleoptera: Tenebrionidae) on seed-borne fungi. Ann Entomol Soc Am 59:192-201

Sokal RR, Sonleitner FJ (1968) The ecology of selection in hybrid populations of Tribolium castaneum. Ecol Monogr 38:345-379

Sokoloff A (1977) The biology of Tribolium with special emphasis on genetic aspects. Volume 3. Clarendon Press, Oxford

Sokoloff A, Franklin IR, Overton LF, Ho FK (1966) Comparative studies with Tribolium (Coleoptera, Tenebrionidae)-I: Productivity of $T$. castaneum (Herbst) and T. confusum Duv. on several commercially-available diets. J Stored Prod Res $1: 295-311$

Soliman MH (1972) Correlated response to natural selection in laboratory populations of Tribolium castaneum. Can J Genet Cytol 15:971-978

Soliman MH (1987) Ageing and parental age effects in Tribolium (review). Arch Gerontol Geriatr 6:43-60

Soliman MH, Lints FA (1975) Longevity, growth rate and related traits among strains of Tribolium castaneum. Gerontologia $21: 102-116$

Sommer RJ (2009) The future of evo-devo: model systems and evolutionary theory. Nat Rev Genet 10:416-422

Sonleitner FJ, Gutherie J (1991) Factors affecting oviposition rate in the flour beetle Tribolium castaneum and the origin of the population regulation mechanism. Res Popul Ecol 33:1-11

South A, Sirot LK, Lewis SM (2011) Identification of predicted seminal fluid proteins in Tribolium castaneum. Insect Mol Biol 20:447-456

Stephens PA, Sutherland WJ, Freckleton RP (1999) What is the allee effect? Oikos 87:185-190

Stevens L (1989) The genetics and evolution of cannibalism in flour beetles (genus Tribolium). Evolution 43:169-179

Stevenson BJ, Cai L, Faucher C, Michie M, Berna A, Ren Y et al. (2017) Walking responses of Tribolium castaneum (Coleoptera: Tenebrionidae) to Its aggregation pheromone and odors of wheat infestations. J Econ Entomol 110:1351-1358

Stewart GS, Morris MR, Genis AB, Szúcs M, Melbourne BA, Tavener SJ et al. (2017) The power of evolutionary rescue is constrained by genetic load. Evol Appl 10:731-741

Stork NE, McBroom J, Gely C, Hamilton AJ (2015) New approaches narrow global species estimates for beetles, insects, and terrestrial arthropods. Proc Natl Acad Sci USA 112:7519-7523

Surtees G (1963) Laboratory studies on dispersion behaviour of adult beetles in grain. III.-Tribolium castaneum (Hbst.) (Coleoptera, Tenebrionidae) and Cryptolestes ferrugineus (Steph.) (Coleoptera, Cucujidae). Bull Entomol Res 54:297-306

Suzuki T (1980) 4,8-Dimethyldecanal: the aggregation pheromone of the flour beetles, Tribolium castaneum and T. confusum (Coleoptera: Tenebrionidae). Agric Biol Chem 44:2519-2520
Szúcs M, Melbourne BA, Tuff T, Hufbauer RA (2014) The roles of demography and genetics in the early stages of colonization. Proc R Soc B-Biol Sci 281:20141073

Szúcs M, Melbourne BA, Tuff T, Weiss-Lehman C, Hufbauer RA (2017) Genetic and demographic founder effects have long-term fitness consequences for colonising populations. Ecol Lett 20:436-444

Szúcs M, Vahsen ML, Melbourne BA, Hoover C, Weiss-Lehman C, Hufbauer RA (2017) Rapid adaptive evolution in novel environments acts as an architect of population range expansion. Proc Natl Acad Sci USA 114:13501-13506

Tigreros N, Lewis SM (2011) Direct and correlated responses to artificial selection on sexual size dimorphism in the flour beetle, Tribolium castaneum. J Evol Biol 24:835-842

Tribolium Genome Sequencing Consortium, Richards S, Gibbs RA, Weinstock GM, Brown SJ, Denell R et al. (2008) The genome of the model beetle and pest Tribolium castaneum. Nature 452:949-955

Vahsen ML, Shea K, Hovis CL, Teller BJ, Hufbauer RA (2018) Prior adaptation, diversity, and introduction frequency mediate the positive relationship between propagule pressure and the initial success of founding populations. Biol Invasions 20:2451-2459

Van Allen BG, Bhavsar P (2014) Natal habitat effects drive densitydependent scaling of dispersal decisions. Oikos 123:699-704

Van Allen BG, Rudolf VHW (2013) Ghosts of habitats past: environmental carry-over effects drive population dynamics in novel habitat. Am Nat 181:596-608

Van Allen BG, Rudolf VHW (2015) Habitat-mediated carry-over effects lead to context-dependent outcomes of species interactions. J Anim Ecol 84:1646-1656

Vasudeva R, Sutter A, Sales K, Dickinson ME, Lumley AJ, Gage MJ (2019) Adaptive thermal plasticity enhances sperm and egg performance in a model insect. Elife 8:e49452

Verheggen F, Ryne C, Olsson POC, Arnaud L, Lognay G, Högberg $\mathrm{HE}$ et al. (2007) Electrophysiological and behavioral activity of secondary metabolites in the confused flour beetle, Tribolium confusum. J Chem Ecol 33:525-539

Via S (1999) Cannibalism facilitates the use of a novel environment in the flour beetle, Tribolium castaneum. Heredity 82(Pt 3):267-275

Wade MJ (1980a) Effective population size: the effects of sex, genotype, and density on the mean and variance of offspring numbers in the flour beetle, Tribolium castaneum. Genet Res 36:1-10

Wade MJ (1980b) An experimental study of kin selection. Evolution 34:844-855

Wade MJ, Beeman RW (1994) The population dynamics of maternaleffect selfish genes. Genetics 138:1309-1314

Wade MJ, Chang NW, Mcnaughton M (1995) Incipient speciation in the flour beetle, Tribolium confusum - premating isolation between natural populations. Heredity 75:453-459

Wade MJ, Goodnight CJ (1998) Perspective: the theories of Fisher and Wright in the context of metapopulations: when nature does many small experiments. Evolution 52:1537-1553

Wade MJ, Johnson NA (1994) Reproductive isolation between two species of flour beetles, Tribolium castaneum and T. freemani: variation within and among geographical populations of T. castaneum. Heredity 72(Pt 2):155-162

Wade MJ, Johnson NA, Jones R, Siguel V, McNaughton M (1997) Genetic variation segregating in natural populations of Tribolium castaneum affecting traits observed in hybrids with $\mathrm{T}$. freemani. Genetics 147:1235-1247

Wade MJ, Shuster SM, Stevens L (1996) Inbreeding: its effect on response to selection for pupal weight and the heritable variance in fitness in the flour beetle, Tribolium castaneum. Evolution 50:723-733

Weiss-Lehman C, Tittes S, Kane NC, Hufbauer RA, Melbourne BA (2019) Stochastic processes drive rapid genomic divergence during experimental range expansions. Proc R Soc B-Biol Sci 286:20190231 
Wexler Y, Scharf I (2017) Distinct effects of two separately applied stressors on behavior in the red flour beetle. Behav Process 145:86-92

Wexler Y, Subach A, Pruitt JN, Scharf I (2016) Behavioral repeatability of flour beetles before and after metamorphosis and throughout aging. Behav Ecol Sociobiol 70:745-753

Wexler Y, Wertheimer K-O, Subach A, Pruitt JN, Scharf I (2017) Mating alters the link between movement activity and pattern in the red flour beetle: the effects of mating on behaviour. Physiol Entomol 42:299-306

Williams GC (1975) Sex and evolution. Princeton University Press, Princeton NJ

Winther RG, Giordano R, Edge MD, Nielsen R (2015) The mind, the lab, and the field: three kinds of populations in scientific practice. Stud Hist Philos Biol Biomed Sci 52:12-21

Wong N, Lee C-Y (2011) Relationship between population growth of the red flour beetle Tribolium castaneum and protein and carbohydrate content in flour and starch. J Econ Entomol 104:2087-2094

Wright S (1932) The roles of mutation, inbreeding, crossbreeding, and selection in evolution. na

Wright S, Dobzhansky T (1946) Genetics of natural populations; experimental reproduction of some of the changes caused by natural selection in certain populations of Drosophila pseudoobscura. Genetics 31:125-156

Yamada Y (1974) Tribolium as a biological model in quantitative genetics. 1st World Congress on Genetics Applied to Livestock Production, Proc 1:439-450
Yamauchi H, Harada M, Miyanoshita A (2018) Polymorphism observed in mitochondrial genes of red flour beetle, Tribolium castaneum (Coleoptera: Tenebrionidae) of different origin in laboratory cultures. Biosci Biotechnol Biochem $82: 229-231$

Yan G, Stevens L, Goodnight CJ, Schall JJ (1998) Effects of a tapeworm parasite on the competition of Tribolium beetles. Ecology 79:1093-1103

Yezerski A, Gilmor TP, Stevens L (2004) Genetic analysis of benzoquinone production in Tribolium confusum. $\mathrm{J}$ Chem Ecol 30:1035-1044

Young AM (1970) Predation and abundance in populations of flour beetles. Ecology 51:602-619

Ziegler JR (1972) Maintenance and regulation of unconfined populations of Tribolium, the flour beetle. University of Chicago, Chicago

Ziegler JR (1976) Evolution of the migration response: emigration by Tribolium and the influence of age. Evolution 30:579-592

Ziegler JR (1977) Dispersal and reproduction in Tribolium: the influence of food level. J Insect Physiol 23:955-960

Ziegler JR (1978) Dispersal and reproduction in Tribolium: the influence of initial density. Environ Entomol 7:149-156

Zirkle DF, Dawson PS, Lavie B (1988) An experimental analysis of the genetic relationships among life-history traits and emigration behavior in Tribolium castaneum. Oikos 53:391-397

Zromska-Rudzka H (1966) Abundance and emigrations of Tribolium in a laboratory model. Ekol Polska, Seria A 14: 491-518 